\title{
Assessing the prevalence of urogenital schistosomaisis and transmission risk factors amongst school-aged children around Mapé dam ecological suburbs in Malantouen district, Cameroon
}

\author{
Adeline P. Mewabo ${ }^{1}$, Roger S. Moyou², Lysette E. Kouemeni' ${ }^{1}$, Jeanne Y. Ngogang ${ }^{1}$, Lazare Kaptue ${ }^{1}$
} and Ernest Tambo ${ }^{1,3^{*}}$

\begin{abstract}
Background: Urogenital schistosomiasis is a parasitic infection of public health importance that affects over 112 million people worldwide. The study aimed at assessing the urogenital schistosomiasis prevalence and risk factors of transmission around Mape dam suburds in Malantouen district, West, Cameroon.

Methods: The study was conducted using semi-structured pretested questionnaires to collect socio-demographic and ecological data. Urine samples were also collected and used to confirm the prevalence of schistosomiasis in consented school-aged children in four primary schools between March - July 2014. Snails' samples around the dam surburbs were also collected for taxonomy characterization and species identification. Data were compiled and quality control assessed and analysed using SPSS version 17 and Epiinfo data 3.1. $P<0.05$ was considered statistical significance.

Results: Questionnaires were administered to 229 pupils, with gender ratio of $1.04(\mathrm{~m} / \mathrm{f})$. The prevalence of schistosomiasis haematobium was $16.6 \%$. Mambonko school site, which is the closest to the dam suburbs, registered the greatest prevalence rate of $40 \%$. The age group beween 10-13 years was the most infected (18.3\%) and boys were more infested than girls (21.0\% vs. $15.5 \%$ ). Haematuria, urination pain, school absentiesm and poor performance were the major recorded complications in 39.5 and $26.3 \%$ males to female respectively. Infection rate gender disparity documented is still poorly understood and Bulinus truncatus collected from Mambonko suburb as potential snail intermediate host requires further studies.
\end{abstract}

Conclusions: Authors advocated that schools and dam suburds sustained and innovative community-based surveillance and response targeted interventions implementation are needed to inform and support decisionmaking policy, but also in improving effective contextual behavioural communication changes and MDA improved uptake measures on national schistosomiasis control and elimination in Cameroon.

Keywords: Urogenital schistosomiasis, Pupils, Schistosoma haematobium, Prevalence, Risk factors, Mapé dam

\footnotetext{
* Correspondence: tambo0711@gmail.com

'Department Biochemistry, Higher Institute of Health Sciences, Université des

Montagnes, Bangangté, Cameroon

${ }^{3}$ Africa Disease Intelligence and Surveillance, Communication and Response

(Africa DISCoR) Institute, Yaoundé, Cameroon

Full list of author information is available at the end of the article
} 


\section{Multilingual abstracts}

Please see Additional file 1 for translation of the abstract into the five official working languages of the United Nations.

\section{Background}

Globally, Schistosomiasis is reported in 93 countries, accounts for more than 600 million vulnerable individuals with about 200 million infected people [1]. In tropics and sub-tropics, human and water contacts can be potential risk factor of schistosomiasis. Fresh waters, natural and artificial dams are areas where schistosomiasis infection and transmission dynamic take place [2]. The persistence human infection has been directly linked to contact with fresh water infested with snail intermediate host during fishing and swimming in ponds or dam water, and increasing contact with agricultural and irrigation contaminated water systems $[2,3]$. It is documented that six schistosomes species are responsible for human schistosomiasis, but there are more commonly reported in literature namely (Schistosoma) $S$. haematobium, S. mansoni and S. intercalatum in Africa and particularly in Cameroun [4]. Globally, S. haematobium is the most prevalent species and accounts for about 112 million vulnerable populations and 80 million cases and 150000 deaths annually. More than $85 \%$ of infested populations are severe and mainly found in sub-Saharan Africa, where more than 20 million suffered from a severe form of schistosomiasis complications, resulting to about 200000 deaths annually $[3,4]$. The socioeconomic consequences on developing countries is enormous, especially in Africa where it constitutes a major public health burden in riskiest children group impeding school attendance, absenteism illed-health and weak memory, poor performance and productivity, disability and death $[1,4,5]$.

In Cameroun, more than 5 million people are at risk of schistosome infection, estimated 2 million are infected and mainly children/pupils between the ages of 6-15 years old made up the most vulnerable groups, followed by fishersmen/women and farmers $[5,6]$. Historically, between 1949-1951, the two first sites of S. haematobium were reported by field workers in fishermen in BarombiMbo dam in kumba in South-Western region of Cameroon, where the prevalence was $100 \%$. By 1960 s, the tier site was reported in Loum, later in Nothern and Western areas of Cameroon in 1981 (Kekem) [7, 8]. S. mansoni was documented in fish ponds around olézoa in Yaoundé, in 1978 southern part around $60 \mathrm{~km}$ from Nkolmébanga near Sa'a closer to Sanaga river $[2,6,9]$. In 1981, the same species ( $S$. mansoni) was reported in Northeners in Cameroun with a prevalence ranging from $4.9 \%$ (Koza) to $52.2 \%$ (Dougué) $[10,11]$. S. intercalatum was reported on 67 patients in nursery school in Eséka in Cameroon in 1966, and was later reported in Obala, Mbalmayo, Edéa, Bokito and Yaoundé settings. Yaoundé, the capital reported very high prevalence rate due to inadequacies in WASH (water, sanitation and hygiene) programs implementation in urban/semi-urban settings, water scarcity and infestation in built fish ponds in Mélen, Obili et Olézoa districts with an overall prevelance of (24.3\%) [12]. Recently, S. haematobium is unevenly distributed, more prevalent in unstable northern regions and refugees camps around the borders areas with Nigeria and central Africa Republic compared to Western, South-West and littotal provinces of Cameroon [12,8].

Very few reports, data and records are available on the urogenital schistosomiasis in Western region of Cameroon. It documented that schistosomiasis epidemics occurred in schools environment in Magba district, Noun department in 2012, and mass praziquantel administration (MPA) has been implemented in the locality $[2,5,6]$. Since then, little consistent and comprehensive efforts in gathering quality data and information has been documented in understanding, the ecological and epidemiogical determinants of persistent schistosomiasis endemicity and flash epidemics. As Mape dam and linked fresh water rivers suburds are still inhabited by low resource populations of farmers and herbers that appear favorable conditions to parasite and hosts abundance and competence from Western to Nothern regions in Cameroon [2, 5, 9].

This study aimed at determining the prevalence of urogenital schistosomiasis and epidemio-ecological risk factors indices in school-aged children attending public schools and residing around Mape dam suburbs, in Malantouen health district in West province, Cameroon.

\section{Methods}

\section{Study site}

The school-based study was conducted around the Mape dam, built in July 1987, with a maximum water level of $715 \mathrm{~m}$. It covers an area of about $550 \mathrm{~km}$ from Adamaoua, Magba-West and North-West area in Malentouen health district. Magba is one of the nine districts, more than twenty ethnic groups (Bamon, kotoko, Bayou...) and located in Noun department in West, Cameroon. With an estimated population of 35628 and density of 30 inhabitants per $\mathrm{km}$, it is located in $5{ }^{\circ} \mathrm{N}$ and $6{ }^{\circ} \mathrm{N}$ latitude and $11{ }^{\circ} \mathrm{E}$ to $12{ }^{\circ} \mathrm{E}$ longitude. The equator climate is made up of 2 seasons: a short dry season (November to March), with temperature ranging from 30-35 ${ }^{\circ} \mathrm{C}$ and a longer raining season (April to October), with tempearure ranged $27-28{ }^{\circ} \mathrm{C}$. The vegetation is dense savana, often mouldy. Agriculture and fishing have been common practice and account for $60-70 \%$ of economy and wealth source. Within structured institutional, administrative and traditional systems, schools are located in Matta and Magba villages in Malantouen district. The prevelance of urogenital schistomosomaisis was documented in school-aged children from Mape dam schools suburds, Malantouen distric (Fig. 1). 


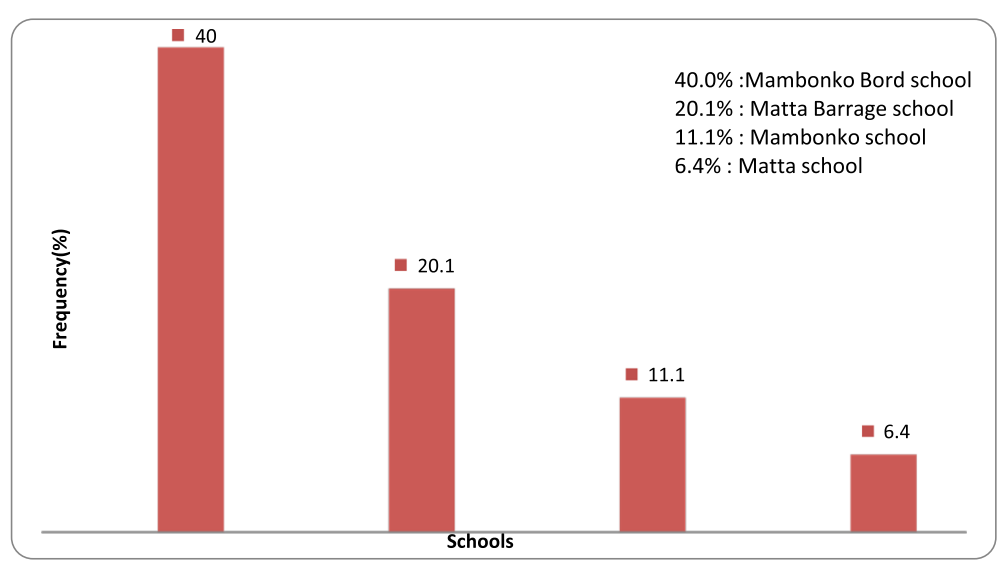

Fig. 1 Prevelance of urogenital schistomosomaisis in school-aged children from Mape dam schools suburds, Malantouen district, West cameroon

\section{Study duration and target population}

The study was conducted within the maximum of two kilometers from the Mape dam in the health district of Malantouen in Western province of Cameroon. Stratified random sampling was deployed to select four public primary schools at varied distance from the dam namely Mambonkobord, Matta Barrage, Mambonko and Matta located at about $200 \mathrm{~m}(\mathrm{~m}), 800 \mathrm{~m}, 1 \mathrm{~km}$ and $2 \mathrm{~km}$ respectively. It covered a period of March to July 2014 and total of 229 pupils were randomly selected and enrolled according to class and school locality where pupils' urine samples and data were collected.

\section{Inclusion criteria}

Primary schools pupils in either classes 2, 3, 4 and 5 residing within $2 \mathrm{~km}$ from the Mape dam and have obtained an informed consent from the parents or legal tutor/guardian and no access to Praziquantel or other antihelmintic agents for the last 2 months were included in the study. A registered pupil in any of the selected four schools that was diagnosed with urogenital schistosomiasis was treated with praziquanted based on infected pupil body weight $(\mathrm{Kg})$ and follow up for 2 months.

\section{Sample collection and processing}

Community engagement in the selected districts were conducted with the support of local traditional, administrative and environmental sanitation authorities as well as pupils and their parents around Mape dam prior to the commencement of the study. Thereafter, further investigation to map and define schools proxy to Mape dam, water ponds and water-needs related activities in the selected villages. A pre-planned field direct physical snail samples search was perfomed using metallic tool around Mape dam and mapped neigbouring fresh river sources including aquatic plants, agricultural and fishing activities by trained staff. Snail samples were collected and placed in adequate container with fesh water, and transported to the laboratory at the Medical and Plants Research Institute (IMPM), Cameroon, where taxonomic characterization were performed.

Pupils were once again sensitized and educated on schistosomiasis prevention and control prior informed consent and enrollment. Each consented pupil received a pre-labeled contained for urine sample collected after a mild physical exercice. All data and information from pupils; and potential risk factos of urogenital schistosomiasis in the locality, clinical manifestations were recorded. Urine samples were preserved in formol solution ( $10 \%$ solution of formaldehyde in water) and transported to IMPM laboratory for further processing based on [13].

\section{Data analysis}

Data were compiled and quality control assessed through a double blind process in SPSS version 17 and Epi info data version 3.1 and analysed. The chi-square (Khi2) statistics and Pearson tests were used to define the prevalence and statistical significance. A logistic regression was also performed to remove or reduce confounders. $P$ value less than 0.05 was considered statistically significant.

\section{Results}

A randomized and semi-stratified descriptive study was performed on pupils in four (4) public primary schools located within a sphere of $2 \mathrm{~km}$ of Mape dam, Malatouen health district, West Cameroon. A total 229 primary school-aged children, 7-16 years old from classes 2, 3, 4 and 5 were enrolled. Urine samples were collected from each enrolled and consented child parents, and further laboratory tested. 


\section{General characteristics of the study}

The average age of enrolled pupils was $11 \pm 1.87$ years old. There were 117 (51\%) males and112 (49\%) females, gender ratio of 1.04, based on the overall pupils populations in Malentoune district. Table 1 indicated that 120 (52.4\%) of pupils have aged ranging within 10-13 years old (Table 1). More than half (61\%) of pupils were schooling in public schools in Matta-dam $(P=0.01)$, followed by matta (27.1\%) in Makounbo villages (Fig. 1).

\section{Assessing age-stratified distribution of school-aged chil- dren population}

Our results showed that the prevalence of infection was significantly associated with school-aged children residence duration in the area 5-10 years (28.9\%) and 1012 years $(39.5 \%)(P=0.55)$. Nonetheless, this prevalence increased with duration of stay and declined from 15 years, probably due to acquired immunity. The mean duration was $9 \pm 3.02$ years old. Our results showed that $38(16.6 \%)$ of the studied pupils were infected. Gender- and age-adjusted schistosomiasis prevalence was recorded in $40 \%$ and was statistically significant in Mambonkobord, being the closest community to Mapé dam $(P=0.01)$. Pupils aged $10-13$ years old were more infected (18.3\%), with male gender (18.0\%) more infested than female (15.1\%) due to regular swimming, fishing and other related activities (Table 2).

\section{Prevalence of schistosomiasis infection linked to water sources contact}

The prevalence of S. haematobium infection was 60\%, from pupils that four times per week to the river/dam. $97.4 \%$ of the studied pupils were in direct contact with dam water $(P=0.01)$. A total 193 pupils $(84.3 \%)$ used river and dam water for different activities including fishing and farming, laundering, bathing and cleaning of household utensils at least four times per week. The distribution of infection (89.2\%) was uneven as the timing for water activities was unspecific and not regular amongst pupils contact with water sources and/or used of shared school latrines (Fig. 2).

Table 1 Age and gender stratified pupils' population distribution in Malentouen, Cameroon

\begin{tabular}{|c|c|c|c|c|c|}
\hline \multirow[t]{2}{*}{ Age (years) } & \multicolumn{5}{|c|}{ Gender } \\
\hline & \multicolumn{2}{|c|}{ Male $n(\%)$} & \multicolumn{2}{|c|}{ Female $n(\%)$} & \multirow{2}{*}{$\begin{array}{l}\text { Total } \\
4(20.5)\end{array}$} \\
\hline$[7-10]$ & 23 & (19.6) & 24 & $(21.4)$ & \\
\hline [10-13] & 62 & (53) & 58 & (47.3) & $120(52.5)$ \\
\hline [13-16] & 32 & (27.3) & 30 & $(26.8)$ & $62(27)$ \\
\hline Total & 117 & (51) & 112 & (49) & $229(100)$ \\
\hline
\end{tabular}

Table 2 Prevalence S. haematobium based on residence duration in Malantouen District, Cameroon

\begin{tabular}{llll}
\hline $\begin{array}{l}\text { Duration of residence } \\
\text { in the site (years) }\end{array}$ & $\begin{array}{l}\text { Prevalence of S. haematobium } \\
\text { in urine }\end{array}$ & Total \\
\cline { 2 - 3 } & Yes $n(\%)$ & No $n(\%)$ & $n(\%)$ \\
\hline $1-5$ & $6(15.8)$ & $22(11.5)$ & $28(12.2)$ \\
$5-10$ & $11(28.9)$ & $60(31.4)$ & $71(31)$ \\
$10-12$ & $15(39.5)$ & $62(32.5)$ & $77(33.6)$ \\
$12-15$ & $6(15.8)$ & $47(24.6)$ & $53(23.1)$ \\
Total & $(100)$ & $191(100)$ & $229(100)$ \\
\hline
\end{tabular}

\section{Clinical characteristics of studied population}

Hematuria prevalence rate was reported in $39.5 \%$ and was statistically significant $(P=0.05)$; and $26.3 \%$ of pupils had recorded painful micturition (s). The prevalence of pupils that have received praziquantel treatement within three months before urine samples collections was 224 (98\%) (Tables 3 \& 4).

\section{Assessment of risk factors of $S$. haematobium infestation and schistosomiasis infection}

Risk factors documented in the four schools surrounding settings included the lack of hygiene and sanitation, ignorance and lack of knowledge of the disease and the tropical ecology (relative temperature: $22-28{ }^{\circ} \mathrm{C}$, preferable sites of the snail sample at depth of water root and stem or death leaves of $20-30 \mathrm{~cm}$ ), that favour the development of snail intermediate host. The intermediate host of $S$. haematobium documented belongs to the family of Bulinidea, genius Bulinus made up of four subtypes namely: africanus, tropicus, truncatus, forskali. Also, the development of hydroelectric and agricultural policy and practice in the areas also provided another favorable biotic environment for snail development and infestation. Continuously, fishermen and farmers have been exposed to such infestation since the works involve permanent and frequent contact with water of unknown risks and determinants, requiring urgent implementation of community-based schistosomiasis risk factors surveillance and targeted interventions such as mhealth schistosomiasis strategies innovations in behavioural changes coupled with improved communities (WASH) water, sanitation and hygiene programs benefits.

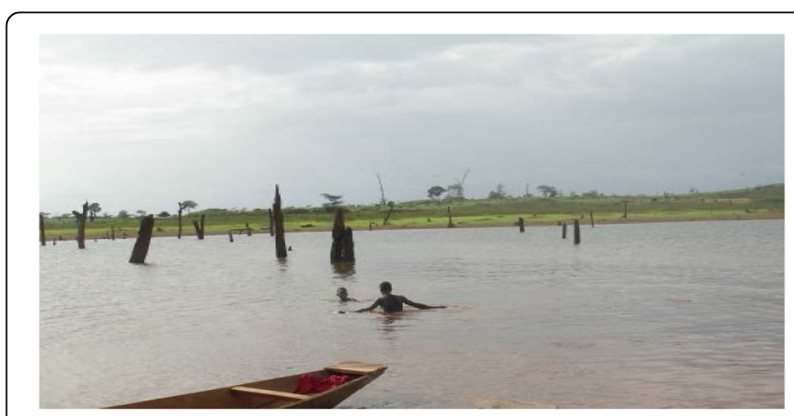

Fig. 2 Mape Dam landscape with fishermen swimming 
Table 3 Gender and age stratified distribution of studied pupils in Malentouen District, Cameroon

\begin{tabular}{|c|c|c|c|c|c|c|c|c|c|}
\hline \multirow[t]{2}{*}{ Age(years) } & \multicolumn{3}{|l|}{ Male } & \multicolumn{3}{|c|}{ Female } & \multicolumn{3}{|l|}{ Total } \\
\hline & Total & Positive & $(\%)$ & Total & Positive & (\%) & Total & Positive & $(\%)$ \\
\hline$[7-10]$ & 23 & 3 & (13.0) & 24 & 4 & (16.6) & 47 & 7 & (14.8) \\
\hline [10-13] & 62 & 13 & (21) & 58 & 9 & (15.5) & 120 & 22 & (18.3) \\
\hline [13-16] & 32 & 5 & (15.6) & 30 & 4 & (13.3) & 62 & 9 & (14.5) \\
\hline Total & 117 & 21 & (18) & 112 & 17 & (15.1) & 229 & 38 & (16.6) \\
\hline
\end{tabular}

(\%)- Percentage

\section{Discussions}

Schistosomiasis is still a serious public health challenge in most remote settings in Africa. It is caused by the presence of $S$. haematobium in the blood vessels, and transmitted to man by an intermediate snails host in fresh water, dams and ingestion of infected food products or shared risky public schools latrines. These results showed that a total 229 pupils, aged 7-16 years old were investigated from four public primary schools located within a sphere of $2 \mathrm{~km}$ from Mape dam, Malantouen health district, West Cameroon. The average age of enrolled pupils was $11 \pm 1.87$ years old. There were 117 (51\%) males versus $112(49 \%)$ females, gender ratio of 1.04. Our results showed an average prevalence of $16.6 \%$ was infected with $\mathrm{S}$. haematobium from urine samples laboratory analysis on any of the selected primary shools of the studied pupils from classes 2 to 5 . These findings are consistent with similar studies reported on schools adolescents in Burkina Faso and Mali in West Africa and previously in northern dams in Cameroon $[6,8,12,13]$ Similarly, previous studies in Africa have documented the persistent of schistosmiasis in Africa. These include Congo, Cote d Iviore, Cameroon, Zimbabwe, Sudan, urogenital schistosomiasis in Pool region, on 1337 pupils with a prevalence of infestation of $15.63 \%$ carried S. haematobium eggs and the intermediate host characterized was Bulinus truncatus [7, 8, 13-15]. In Ivory Coast, a parasitological study showed that on 724 pupils reported an infestation rate of $12.6 \%$ of same species in the region of Agnéby [15, 16]. Males' infection was higher than female directly linked to males' behaviours, attitudes and cultural activites. In

Table 4 Presenting clinical signs and symptoms amongst studied pupils in Malentouen district, Cameroon

\begin{tabular}{llllll}
\hline & \multicolumn{4}{l}{$\begin{array}{l}\text { Presence of S.haematobium in } \\
\text { the urine Percentage (\%) }\end{array}$} \\
\cline { 2 - 6 } & \multicolumn{4}{c}{ Yes $n(\%)$} & \multicolumn{3}{c}{ No $n(\%)$} \\
\hline Pruritis & Yes & 0 & $(0)$ & 0 & $(0)$ \\
& No & 38 & $(100)$ & 191 & $(100)$ \\
Painful micturition & Yes & 10 & $(26.3)$ & 8 & $(4.2)$ \\
Macroscopic hematuria & No & 28 & $(73.7)$ & 183 & $(95.8)$ \\
& Nes & 15 & $(39.5)$ & 21 & $(11)$ \\
& No & 23 & $(60.5)$ & 170 & $(89)$ \\
\hline
\end{tabular}

Sénégal, Niger and Mali, transversal or cross-sectional studies on risk factors and prevalence in school environment reported prevalence ranged of $30.2-72.0 \%$ and risk factors were mainly male and frequent visits and activities in fresh or dam or river water $[5,6,9,12,16,17]$.

Gender- and age-adjusted prevalence of schistosomiasis was $40 \%$ in school pupils and was statistically significant, mainly in Mambonkobord school, being the closest community to Mapé dam $(P=0.01)$. Pupils aged $[8,10-12]$ years old were more infected (18.3\%), and the prevalence in male gender was more than female at (18.0) and (15.1\%) respectively. The prevalence rate of $S$. haematobium infection to Mape dam was $60 \%$, from pupils that four times per week into fresh river and dam. This result was high compared to results obtained previously in other southern and western areas in Cameroon. 37 (97.4\%) were in contact with dam water $(P=0.01)[3,10,13,16]$. A total 193 pupils (84.3\%) used river and dam water for bathing, fishing and cleaning of household at least 4 times per week. The distribution of infestation (89.2\%) was uneven as the timing for water activities was unspecific and irregular amongst pupils $[14,15]$.

In terms of presence of schistosomiasis, these results are consistent with those of Deschiens in 1968 that found same three species namely $S$. mansoni, S. haematobium and $S$. intercalatum. Other epidemiological studies showed the existence of different sites that varied from regions and prevalence in men. For example the prevalence of $S$. haematobium in villages closer to SEMYI (Noulthohim, waiddoua, Madalan, Birnindel, Godjo and Maga) ranged between $44.5-61.0 \%$ and the intermediate host identified B. truncatus and B. globusus in Northern Cameroon; whereas a radio-epidemiologic study on urogenital schistosomiasis in Barombi (South-West) and recorded a prevalence higher than that documented BarombiKotto and BarombiMbo of 76 and $50 \%$ respectively $[3,5,14,16-18]$. This intensity was not influenced by gender and age, which is opposed to our finding that showed that male were more susceptible than female. The commonest intermediate host was $B$. camerunensis and $B$. truncates, with an infestation rate $17.2 \%$. In 2003 Njiokou [4] showed the compatibility between linked urogenital schistosomiasis and S. heamatobium with B. truncatus and B. globusus in Cameroon. 
Recently, Boko-Haram uprising and political instability in Northern Nigeria and Central Africa Republic having huge impact (e.g., Shelther, sanitation and water scarcity, food insecurity/shortage, poor care and population displacement), and cross border movement and displacement situation continues to worsen in refugees' camps healthcare delivery and local inhabitants emergency disaster crisis in Northern and Eastern regions of Cameroon and requires urgent humanitarian emergency response resources and long-term capacity support.

Our finding showed that pupils age varied 7-16 years old were the dynamic group to fishing, swimming, bathing, washing and cleaning in dam water or irrigation farming activities those facilitating schistosomiasis transmission dynamics and persistence. The gender (M/F) ratio was 1.04 . Our results were similar to those obtained on pupils aged $5-15$ years old and ratio 1.36 , but the age group [8, 10-12] years old had the high prevalence of $18.3 \%$; while another study reported higher prevalence of $47 \%$ found in pupils between $6-10$ years old $[13,14]$. There was statistically significant difference between prevalence and gender (male). Pupils from Mambonkobord public school, the closest to the Mape dam were infected and this finding was consisistent with previous studies $[7,8,15]$. The reasons include the proxy and frequent contact or visit to the dam compared to those from distant villages. Since about $97.4 \%$ of infested pupils have had contact with Mape dam water, we concluded that Mape dam is the primary site of urogenital schistosomiasis incidence and prevalence in this locality [7, 15]. Pupils play an important role in the transmission dynamics which is consistent with previous findings in cameroon and other endemic areas of Africa [6, 17, 19]. This confirms that hydrolytic management constitues a significant factor S. haematobium. It was documented that children are in constant contact with water partially or completely during washing/bathing, swimming and cleaning households' tools and this allow cercariae to infect them. Similarly, previous studies documented that the snail breeding sites and transmission dynamics were conditioned directly by either the abundance in miracidium larva in water or by human urination in aquatic environment and increasing the probability of water infestation $[5,6,9,12]$. Swimming and bathing in stagnant water was also a positive factor in schistosomiasis emergence in domestic gardens and rice farming and consistent with previous findings $[14,18,19]$. The presence of $B$. truncatus in this site confirmed that it is favorable for the development and proliferation of snail, which is consistent with observations consistent with similar endemic S. haematobium studies across Africa [3, 5, 9, 12, 15, 20]. Hence, understanding snail ecology and climatic change influence on abundance and transmission dynamics is essential in risk mapping and evidence-based intermediate host interruption interventions.
A total of $39.5 \%$ of infection rate was linked with the duration of stay (10-11 years) in the residential site or suburd(s). This result was weak compared to previous studies $[4,7,11,14,18]$ that reported $87.5 \%$ of patients that never left the village since they were born. However, pupils that have been lived in the locality for $12-15$ years old had a lower prevalence rate of $15.8 \%$, this can be explained by the the acquired immunity developed by these older ages through repeated exposure to infested dam water. Hematuria and painful micturition in studied school-aged children were the commonest clinical signs recorded a prevalence of 39.5 and $26.3 \%$ respectively [20,21]. Our reported schistosomiasis prevalence of $16.6 \%$ was similar to Akouala et al. [7, 22], but low compared to Nkengazong et al. at Barombidam [23-25] in 2013 (69.17\%). This study is consistent previous studies in addition to school absentiesm and poor performance [3, 5, 15, 21, 22, 26-28]. Our findings revealed that epidemio-ecological factors responsible for persistent transmission dynamics included the presence/contact with the dam, traditional fisherman culture, interation between animal-human contaminated Mape dam source of water driking, favourable subtropical climate, landscape of region, residence for at least one year and $2 \mathrm{~km}$ surrounding villages, and no access to Praziquantel or other antihelmintic agents for the last 2 months [2, 9, 15, 18, 22, 28, 29].

Probably, explications could be Barombi locality is known genetic diversity of urogenital schistosomiasis endemcity, intermediate host exposure and migration/motility of the studied population crossed every day to or from their daily activities [24, 30]. The sensitive $B$. truncatus populations were sensitive to all tested $S$. haematobium and can play an important role similar to B. globususin the expansion of schistosomiasis in Cameroon. Nkengazong et al., in 2013 showed that in school settings $S$. haematobium in Kumba, had a prevalence of $69.17 \%$. Bulinus truncatus and camerunensis were the intermediate hosts found in the locality $[25,26,31,32]$. However, local periodic MPA has been reported and might have significantly reduced the rate of water infestation and S. haematobium re-infection and re-introduction or importation and prevalence amongst pupils and population round the dam suburbs including tourists [1, 2, 33, 34].

Study limitations included the study duration, biased and no define key physiochemical characteristics of mollusca sites that may require coupled with appropriate snail or cercariae breeding sites and hosts mapping. In addition, understanding repeated MDA on schistosome resistance emergence prevention and transmission interruption as well as malacology study is crucial in determining the rate of infestation of B.truncatus and better interpretation of the results and outcomes. The rate of infestation of mollusca 
was not determined, since mosllusca were deaths before arrival at the laboratory. There will be need to associate social demographic, behavioural and epidemiological data that depends on the honest answers of the pupils.

\section{Conclusions}

This study showed that the overall prevalence of $S$. haematobium in selected Malantouen health district sites was $16.6 \%$. The proximity factor of Mambonkobord public school to Mape dam had the most prevalent $S$. haematobium infected pupils population and confimed clinical signs and symptoms of hematuria and micturaction pains linked to urogenital schistosomiasis were the most frequent reported in infected pupils in Malantouen health district. The identified B. truncatus may being probably the snail species responsible for the persistent schistosomiasis public health burden in these vulnerable communities. Strengthening evidence-based and sustainable national schistosomiasis community-based surveillance and response programs and interventions implementation should be prioritzed in improving effective contextual behavioural communication changes and improved MDA uptake strategies amongst vulnerable populations. While, leveraging on advances in mhealth approach and social media innovations networks fitness in improving sustained schistosomiasis control and elimination across endemic or epidemic prone-countries including Camerooun.

\section{Additional file}

Additional file 1: Multilingual abstracts in in the six official working languages of the United Nations. (PDF $572 \mathrm{~kb}$ )

\section{Abbreviations}

IMPM: Medical and Plants Research Institute; Kg: Weight; MPA: Mass Praziquantel Administration

\section{Acknowledgments}

Thanks to UdM-CUM staff and technicians for the enabling research environment and technical support.

\section{Funding}

No financial support was received.

Availability of data and materials

All datasets will be made available to the public upon acceptance and publication

\section{Author's contributions}

APM, RSM and LK conceived study and design. APM performed the study and analyzed the data. ET prepared the primary draft of the manuscript. APM, RAM, LK, JYN and ET provided additional information from literature. ET proficiently revised the manuscript. All authors read and approved the final version of the manuscript.

\section{Competing interests}

The authors declare that they have no competing interests.

\section{Consent for publication}

All authors consented for the publication in the journal.

\section{Ethics approval and consent to participate}

Ethics approval and consent to participate was received from the Institutional Ethical Review Board (IERB) of Universite des Montages, Malantouen local government admistrative and traditional authorities approval. Parents were providedwithwritten and verbal information on the study goal, methods, advantages and consequences of the study. Pupils whose parents did not provide an informed consent were excluded from the study. Each pupil file was treated independently and confidentially, and only the data analysis had access to secured data and pupils' information. All pupils diagnosed with $\mathrm{S}$. haematobium were treated with single dose of praziquantel based on their body weight $(\mathrm{kg})$.

\section{Author details}

${ }^{1}$ Department Biochemistry, Higher Institute of Health Sciences, Université des Montagnes, Bangangté, Cameroon. ${ }^{2}$ Institut de Recherches Médicales et d'Etudes des Plantes Médicinale-Centre de Recherches Médicales (IMPM-CRM), Yaoundé, Cameroon. ${ }^{3}$ Africa Disease Intelligence and Surveillance, Communication and Response (Africa DISCoR) Institute, Yaoundé, Cameroon.

Received: 19 April 2016 Accepted: 10 February 2017

Published online: 06 March 2017

\section{References}

1. Richardson ST, Franklin AL, Rome ES, Simms-Cendan JS. Global health: urogenital schistosomiasis in the adolescent Girl. Pediatr Adolesc Gynecol. 2016:29(4):326-32.

2. Knowles SC, Webster BL, Garba A, Sacko M, Diaw OT, Fenwick A, Rollinson D, Webster JP. Epidemiological Interactions between urogenital and intestinal human schistosomiasis in the context of praziquantel treatment across three west African countries. PLoS Negl Trop Dis. 2015;9(10):e0004019.

3. Gurarie D, Yoon N, Li E, Ndeffo-Mbah M, Durham D, Phillips AE, Aurelio $\mathrm{HO}$, Ferro J, Galvani AP, King CH. Modelling control of schistosoma haematobium infection: predictions of the long-term impact of mass drug administration in Africa. Parasit Vectors. 2015;8:529. doi:10.1186/ s13071-015-1144-3.

4. Ntonifor HN, Mbunkur GN, Ndaleh NW. Epidemiolocal survey of urinary schistosomiasis in some primary schools in a new focus behind mount Cameroon, South West region, Cameroon. East Afr Med J. 2012;89(3):82-8.

5. TchuemTchuenté LA, Momo SC, Stothard JR, Rollinson D. Efficacy of praziquantel and reinfection patterns in single and mixed infection foci for intestinal andurogenital schistosomiasis in Cameroon. Acta Trop. 2013;128(2):275-83.

6. Tchuenté LA, Southgate VR, Webster BL, De Bont J, Vercruysse J. Impact of installation of a water pump on schistosomiasis transmission in a focus in Cameroon. Trans R Soc Trop Med Hyg. 2001;95(3):255-6.

7. Djuikwo FF. Bulinus globusus et Bulinustruncatus (Gastropoda: Planorbidae): variabilité génétique et implications dans la transmission de Schistosoma haematobium au Cameroun [thèse]. Médecine: Université de limoges. http:// epublications.unilim.fr/theses/2011/djuikwo-nouboue-felicite-flore/djuikwonouboue-felicite-flore.pdf. Accessed 22 July 2015.

8. Abebe G, Kiros M, Golasa L, Zeynudin A. Schistosoma mansoni infection among patients visiting a health centre near Gilgel Gibe Dam, Jimma, south western Ethiopia. East Afr J Public Health. 2009;6(3):300-2.

9. TchuemTchuenté LA. Lutte contre la schistosomose : défi et perspectives pour XXle siècle. Bull Soc PatholExot. 2006:99(5):372-6.

10. Bausch D, Cline BL. The impact of control measures on urinary schistosomiasis in primary school children in northern Cameroon: a unique opportunity for controlled observations. Am J Trop Med Hyg. 1995;53(6):577-80

11. Adoubryn KD, Ouhon J, Yapo CG, Assoumou EY, Ago KML, Assoumou A. Profil épidémiologique des schistosomoses chez les enfants d'âge scolaire dans la région de l'Agnéby (sud-est de la cote d'ivoire). Bull Soc PatholExot. 2006;99(1):28-31.

12. Poda JN. Maladies liées à l'eau dans les bassins de la Volta: Etats des lieux et perspectives. Volta bassin Focal Projet Report $\mathrm{N}^{\circ} 4 . \mathrm{IRD}$. Montpellier and Colombo; 2007. http://cpwfbfp.pbworks.com/f/BFP+Volta_Poda+(2007).pdf. Accessed 16 July 2015. 
13. Moyou-Somo R, TagniZukam D, Kouamouo J, Enyong P, Ripert C. Epidemiologic and radiologic study of urinary bilharziasis in the focus of Barombi lake, Cameroon. Bull Soc PathoExot. 1987;80(5):813-25.

14. Deribe K, Eldaw A, Hadziabduli S, Kailie E, Omer MD, Mohammed AE, Jamshed T, Mohammed EA, Mergani A, Ali GA, Babikir K, Adem A, Hashim F. High prevalence of urinary schistosomiasis in two communities in South Darfur: implication for interventions. Parasit Vectors. 2011;4:14.

15. Audibert $\mathrm{M}$, Ibrahim $\mathrm{H}$, Hamidou I. Prévalence de la schistosomiase à Schistosoma haematobium dans le Mayo Danai (Nord-Cameroun). Acta Trop. 1983:40:177-86.

16. Njiokou F, Teukeng F, BilongBilong F, Njiné T, SameEboko A. Etude expérimentale de la compatibilité entre Schistosoma haematobium et deux espèces de bulinus au Cameroun. Bull Soc PathExot. 2004;97(1):43-6.

17. Degarege A, Mekonnen Z, Levecke B, Legesse M, Negash Y, Vercruysse J, Erko B. Prevalence of schistosoma haematobium infection among school-age children in afar area, Northeastern Ethiopia. PLoS One. 2015;10(8):e0133142

18. Nkengazong L, Njiokou F, Asongany T. Two years impact of single praziquantel treatment on infection of urinary schistosomiasis in the BarombiKotto focus, Cameroon. Int J Biosci. 2013;3(3):98-107.

19. Senghor B, Diaw OT, Doucoure S, Seye M, Talla I, Diallo A, Bâ CT, Sokhna C. Study of the snail intermediate hosts of urogenital schistosomiasis in Niakhar, region of Fatick, West central Senegal. Parasit Vectors. 2015;8:410. doi:10.1186/s13071-015-1030-z.

20. Brooker S, Donnely, C A, Gyatt, HL. Estimating the number of helmintic infections in the republic of Cameroon from data on infection prevalence in school children. Bulletin de l'Organisation Mondiale de la Santé, 2000; 34, 15-8.

21. Sacko M, Magnussen $P$, Keita AD, Traoré MS, Landouré A, Doucouré A, Madsen $\mathrm{H}$, Vennervald BJ. Impact of schistosoma haematobium infection on urinary tract pathology, nutritional status and anaemia in school-aged children in two different endemic areas of the Niger River Basin, Mali. Acta Trop. 2011;120 Suppl 1:S142-50.

22. Lee $\mathrm{YH}$, Jeong $\mathrm{HG}$, Kong $\mathrm{WH}$, Lee $\mathrm{SH}$, Cho HI, Nam HS, Ismail HA, Alla GN, Oh CH, Hong ST. Reduction of urogenital schistosomiasis with an integrated control project in Sudan. PLoS Negl Trop Dis. 2015;9(1):e3423.

23. Takougang I, Meli J, Fotso S, Angwafo 3rd F, Kamajeu R, Ndumbe PM. Hematuria and dysuria in the self-diagnosis of urinary schistosomiasis among school-children in Northern Cameroon. Afr J HealthSci. 2004; 11(3-4):121-7.

24. Njiokou F, Teukeng E, BilongBilong CF, Njiné T, Same Ekobo A. Experimental study of the compatibility between Schistosoma haematobium and two species of Bulinus in Cameroon]. Bull Soc PatholExot. 2004;97(1):43-6. French.

25. WHO. Schistosomiasis: progress report 2001-2011, strategic plan 20122020. Geneva: World Health Organisation; 2013.

26. Wami WM, Nausch N, Midzi N, Gwisai R, Mduluza T, Woolhouse M, Mutapi F. Identifying and evaluating field indicators of urogenital schistosomiasis-related morbidity in preschool-aged children. PLoS Negl Trop Dis. 2015;9(3):e0003649.

27. Ndamukong KJ, Ayuk MA, Dinga JS, Akenji TN, Ndiforchu VA, Titanji VP. Prevalence and intensity of urinary schistosomiasis in primary school children of the Kotto Barombi health area, Cameroon. East Afr Med J. 2001; 78(6):287-9.

28. Organisation Mondiale de la Sante (OMS). Aide-mémoire $n^{\circ} 115$ de l'organisation mondiale de la santé sur la schistosomiase. Mars. 2013.

29. Krauth SJ, Greter H, Stete K, Coulibaly JT, Traoré SI, Ngandolo BN, Achi LY, Zinsstag J, N'Goran EK, Utzinger J. All that is blood is not schistosomiasis: experiences with reagent strip testing for urogenital schistosomiasis with special consideration to very-low prevalence settings. Parasit Vectors. 2015;8:584.

30. Rollinson D, Webster JP, Webster B, Nyakaana S, Jorgensen A, Stothard JR. Genetic diversity of schistosomes and snails: implications for control. Parasitology. 2009;136:1801-1811.

31. Knopp S, Person B, Ame SM, Ali SM, Muhsin J, Juma S, Khamis IS, Rabone M, Blair L, Fenwick A, Mohammed KA, Rollinson D. Praziquantel coverage in schools and communities targeted for the elimination of urogenital schistosomiasis in Zanzibar: a cross-sectional survey. Parasit Vectors. 2016;9(1):5

32. Leger E, Webster JP. Hybridizations within the Genus Schistosoma: implications for evolution, epidemiology and control. Parasitology. 2016;30:1-16.
33. Tchuem Tchuenté LA, Momo SC, Stothard JR, Rollinson D. Efficacy of praziquantel and reinfection patterns in single and mixed infection foci for intestinal and urogenital schistosomiasis in Cameroon. Acta Trop. 2013; 128(2):275-83.

34. Senghor B, Diaw OT, Doucoure S, Sylla SN, Seye M, Talla I, Bâ CT, Diallo A, Sokhna C. Efficacy of praziquantel against urinary schistosomiasis and reinfection in Senegalese school children where there is a single welldefined transmission period. Parasit Vectors. 2015;8:362.

\section{Submit your next manuscript to BioMed Central and we will help you at every step:}

- We accept pre-submission inquiries

- Our selector tool helps you to find the most relevant journal

- We provide round the clock customer support

- Convenient online submission

- Thorough peer review

- Inclusion in PubMed and all major indexing services

- Maximum visibility for your research

Submit your manuscript at www.biomedcentral.com/submit
) Biomed Central 